Atıf / Citation: Orman, A. \& Sebetci, Ö. 2021. Brand impact on the use of mobile applications. International Review of Economics and Management, 9(2), 200-217. Doi: http://dx.doi.org/10.18825/iremjournal.1011588 (Araştırma Makalesi / Research Article)

\title{
BRAND IMPACT ON THE USE OF MOBILE APPLICATIONS
}

\author{
Abdullah ORMAN ${ }^{1}$ \\ Özel SEBETC $\dot{I}^{2}$
}

Başvuru / Submitted: 20 /10 / 2021-Kabul / Accepted: 08 / 11/ 2021

\begin{abstract}
The study aims to determine whether brand awareness and brand loyalty positively impact mobile application use. A quantitative approach was used to test the proposed model in this study. For this approach, firstly, a trial group was created, and the results were obtained. The participants who did not even use at least one of the travel applications were asked to answer the question, "Which features of the application would be more dominant in selecting the application?". In the study, Cronbach Alpha, Composite Reliability, and Compound Reliability were used for internal consistency, and these values were found to be higher than 0.70 . According to the results, the mean-variance value obtained to evaluate validity was also greater than 0.50 . Therefore, in the model, the brand and other identified factors have been shown to influence the use positively. In the literature, many factors have been examined within the framework of brands and mobile applications. However, in this study, the effect of factors related to the brand, which has not been researched before, on the use of mobile applications was investigated.
\end{abstract}

Keywords: Mobile Applications in Tourism, Brand Image, Brand Awareness, Brand Loyalty, Use of Information Systems Jel Classification: M30, M31

\section{INTRODUCTION}

Companies are increasingly valuing the development and promotion of business and product-level brands, as well as the application of brand rules to ensure brand equality and the implementation of a "brand value strategy."

In the same way, customers choose to associate with brands, be loyal to their favorites, and join in brand communities. Indeed, some customers identify so deeply with a brand that it

\footnotetext{
${ }^{1}$ Asst.Prof., Ankara Yıldırım Beyazıt University, Department of Computer Technologies, aorman@ybu.edu.tr, (D https://orcid.org/00000002-3495-1897

2Asst.Prof., Aydın Adnan Menderes University, Department of Computer Technologies, osebetci@adu.edu.tr, iD https://orcid.org/00000002-2996-0270
} 
becomes an extension of the customer's expanded self. Brand is "A name, term, design, symbol, or other feature that distinguishes a seller's goods or service from the qualities of other vendors," according to the American Marketing Association. A trademark is the legal word for a brand. A trademark can be used to identify a single item, a group of items, or all of the seller's products. When referring to a company, the recommended term is a trading name (Bennett \& Boraas, 1988).

Today it is estimated that more people will access the internet from mobile devices than desktop devices (Green \& Lomanno, 2012) so the brand should not be ignored in users" mobile application preference. Latest mobile services are made possible by the improved computer capacity of portable devices and advancements in network communication. Various mobile applications have been developed to address a wide range of personal and professional user needs These applications can be web-based, local, or hybrid applications (Picoto, Duarte \& Pinto, 2019). It also demonstrates that visitor outcomes are dependent on brand experience, particularly satisfaction, willingness to return, and intent to suggest. As a result, visitor satisfaction is crucial in the subsequent processing of their experiences (Barnes, Mattsson \& Sørensen, 2014).

Adopting mobile applications to buy tourism-related products and services among consumers is quite essential. Research on the brand and mobile app relationship in this context will help mobile app developers, tourism-related organizations, and government agencies promote mobile apps as the preferred tool for online purchases (Tan et al., 2017).

Companies aim to create value for their brands between their potential customers and their existing customers and keep that value created as a long-term relationship between customers and the brand. However, some factors affect customers" preferences, and it is in the hands of companies to keep customers committed to the brand. In order to investigate this situation, research has been done on brand and mobile applications before. These are research related if branded applications are active types of advertising (Bellman et al., 2011); branded applications affect consumers" cognitive and affective brand reactions (van Noort \& van Reijmersdal, 2019) and the extent to which this effect affects the type of branded applications from the' advertisers' point of view (Alnawas \& Aburub, 2016). When the research in the field is examined, it is observed that the effect of brand and its factors on mobile application use is not examined within the framework of a brand and mobile applications. As a theoretical and literature contribution, the effect of brand-related factors not previously studied on mobile application use was investigated in this study. Therefore, this study on the mobile applications 
of world-famous brands used in tourism will shed light on the importance of the brand in the use of mobile applications in other sectors. Accordingly, there was no research on the effect of brand on mobile applications used in the literature, which shed light on the study's purpose. The structural equation model (SEM) was developed for the study, analysis, and evaluation.

\section{LITERATURE REVIEW}

In the literature review, some studies on the effect of branded mobile applications on brand reaction, consumer satisfaction, purchasing intention, and similar issues were found. The primary motivation and originality of this work will be provided in this section.

Van Noort and van Reijmersdal (2019) examined the effects of brand mobile applications on-brand responses. Branded apps are gaining increasing interest as marketing communication platforms. Companies seek to increase their potential customers for their brands and increase added value among existing customers by providing entertainment and information through branded applications. In this context, they tried to understand whether branded applications affect consumers" cognitive and affective brand reactions, whether this varies according to the type of application, and the role that pleasure and elaboration play in this. Within the study's scope, an experiment was conducted to determine that branded applications increase brand responses. In contrast, entertainment applications increase brand responses by causing higher entertainment levels, while Information applications enable higher maturation levels.

Alnawas and Aburub (2016) examined the impact of benefits from interaction with branded mobile apps on consumer satisfaction and purchasing intentions by taking the "uses and satisfies" approach. As part of the study, 358 participants in seven main shopping centers registered in Jordan were surveyed, and some primary findings were revealed. According to the study findings, interaction-based benefits are examined in four key categories: learning, social integration, personal integration, and satisfaction. Social integration and three other types of benefits have been found to affect consumer satisfaction to varying degrees. Among these, only learning and pleasure-based benefits have been found to produce purchasing intentions, and the relationship between consumer satisfaction and purchasing intentions has also been confirmed.

Companies are increasingly integrating augmented reality (AR) applications into mobile applications, making this approach an element of their marketing strategy. Rauschnabel et al. (2019) focused on AR and examined how it can improve brands by taking 
inspiration from mobile-based augmented reality apps. The study found that consumers are inspired by AR applications' benefits as an intermediary between changes in brand attitude. The study found that the benefits consumers get from AR applications inspire them as an intermediary structure for their attitudes to the brand.

Companies strive to meet their target audience's needs and strengthen their connection through innovative mobile applications. In a study conducted by Li and Fang (2019), predecessors of the intention of continuity for branded applications were investigated. Data collected from 497 users were analyzed using the structural equation model. As a result, it was understood that the brand attachment-satisfaction relationship was not repetitive and that both factors positively affected continuity. The study also found that expectation approval affects brand loyalty and perceived benefit. It has been concluded that brand self-conformity affects the relationship with the brand and that perceived complementarity affects perceived usefulness with satisfaction. As companies' competition in the mobile application field increases, companies have to act more quickly to market their own branded applications. Fang's (2019) study investigated the determinants of continued intent and brand loyalty among app users. By analyzing data collected from 634 application users, it has been determined that branded applications effectively establish additional links with customers and provide design guidelines for applications. The study highlights the need to diversify and make the methods that branded applications use to get feedback from the user more effective. Bellman et al. (2011) in their study of the effectiveness of branded mobile phone apps, attempted to measure using a pre-test / post-test experimental design popular mobile phone apps affected brand attitude and purchase intention. The results showed that using these applications had a positive, persuasive effect, increasing interest in the brand's product category and the brand itself. The study found that apps with a knowledge/user-centered approach more strongly influence purchasing intent, and experiential game-like apps showed less success than the average.

Alnawas and Aburub (2016) also examined the impact of benefits from interaction with similarly branded mobile apps on consumer satisfaction and purchasing intentions. Brand benefits create an emotional bond by driving interactions between consumers and the brand (emotional pathway). System features create loyalty to the application by influencing the perceived benefit (utilitarian pathway). The findings were obtained using an online survey. The study, which used partial least squares structural equation modeling, found that both the emotional and utilitarian pathways facilitated application fidelity. The study goes 
beyond the utilitarian path and offers a broader perspective. As the studies in the literature referred to in this section are guiding in the research, it was understood that the factors affecting the use of a branded mobile application in the literature review conducted within the scope of the study were not examined with the structural equation model and there is no indepth research on this subject. The primary motivation of the study is to overcome this gap in the literature.

\section{HYPOTHESES DEVELOPMENT}

This study proposes a model that measures the effects of advertising, perceived quality, and image, which are useful in using mobile applications within the scope of information technologies on the use of mobile application users. While the model was being created, the studies that examined the literature guided our model. Models were created based on brand loyalty, brand awareness, and brand image in studies on brand value. These studies found that consumers who perceived the brand positively tended to develop a greater willingness to buy the product and then actively seek the product in a store. These approaches have been shown to positively affect making customers announce to each other and be willing to pay more for products (Aaker, 1991; Sasmita \& Mohd Suki, 2015; Koniewski, 2012; AlHawari, 2011). Another study investigated the relationship between the use of hotel mobile apps by users and their impact on brand loyalty. It has been determined that mobile hotel applications will positively affect brand awareness, customer participation, and brand loyalty (Kim \& Adler, 2011).

Research in the field is deficient in how the above-mentioned brand-related factors affect the use. Finally, before the model was created, experts were consulted, and the feedback that the factors of Advertisement (BA), Perceived Quality (PQ), Image (BI) could affect the Awareness (BAW) and Loyalty (BL) factors were taken and the assumption that these factors might affect the Usage (BU) factor. The model was created in this context under the supervisionof specialists. Our model's basic structures are examined to estimate the effectiveness of use, and the theoretical foundations that support the relationships it contains are explained below.

\section{III.I. Advertising and Brand Awareness}

There is enough research in the literature about marketing channels, where advertising efforts are part of the model. This is quite natural because these efforts affect the demand and are related to the earnings of the parties (producers and retailers). Brand awareness is one of 
the main objectives of advertising (Sawant, 2012). Advertising aims to make customers aware of a product or service (Maria et al., 2019). Advertising activities are generally divided into activities managed by the brand's (national) manufacturers and retailers and brand advertising by local advertising. Brand advertising aims to build a 'brand's reputation (brand value or goodwill) and determines current and future sales (Pnevmatikos, Vardar \& Zaccour, 2018). For example, Omoruyi and Chinomona (2019) found a strong positive relationship between brand advertising and brand awareness.

Similarly, Khan et al. (2016) determined the positive impact of brand advertising on brand awareness. This study reveals the following hypothesis: Hla: Brand advertising affects brand awareness positively.

\section{III.II. Advertising and Brand Loyalty}

Marketers employ a range of tactics to entice consumers in visually competitive surroundings. By making commercials that are difficult to read and do not direct clients to an interpretation, a communication approach promotes advertising authenticity (Pieters, Warlop \& Wedel, 2002).

Brand loyalty is often referred to as a "biased (non-random) behavioral response (purchase), sometimes expressed by the decision-making unit for one or more alternative brands," and is a function of psychological processes (Jacoby, 1971). Re-patronage intentions, level of satisfaction, brand preference, pricing premium, switching cost, and brand commitment are the six elements of brand loyalty (Aaker, 2009). Brand loyalty can be described as the strength of a consumer's belief in a certain brand. Consumers' decisions about which products/brands to buy are heavily influenced by brand-related information. Consumers see deterministic features in a brand, and being affected by these qualities increases brand commitment (loyalty). The fundamental characteristic of a strong brand is that it attracts a large number of devoted customers.. A brand that strategically develops brand loyalty in its product category can also prevent new products from entering the market (Uztug, 2003). It is said that organizations reaching loyal customers can gain higher market shares, gain higher returns in investment rates, increase bargaining power from various suppliers and distribution channels, and communicate from mouth to mouth (Ahmad, 2011). Ababio and Yamoah (2016) investigated the effect of advertising on brand loyalty and found that advertising played a significant role in brand loyalty. Based on this information, this study examines the relationship between brand loyalty and brand advertising. H1b: Brand advertising positively affects brand loyalty 


\section{III.III. Perceived Quality, Brand Awareness, and Brand Loyalty}

One of the building blocks of brand equity is quality, as perceived by the consumer. Perceived quality is related to strong financial performance. The solid financial performance can be added to the price depending on the product's quality. Consumers are ready to pay more for products and services that they perceive to be of higher quality. However, the quality is in the minds of the consumers. A product must have reached specific quality standards, whether determinants of actual quality (Gross, 2004). The perceived quality leads to positive results, including customer loyalty, customer satisfaction, favorable marketing results, and customer repeat purchasing and/or use of positive words about the brand owned (Ahmad, 2011). H1c: Perceived Quality (PQ) positively affects Brand Awareness. H1d: Perceived Quality $(P Q)$ positively affects a Loyalty

\section{III.IV. Brand Image, Brand Awareness and Brand Loyalty}

Brand image is defined as a representative or objective-subjective set of perceptions in the consumer's mind. Therefore, it can be described as "justified or emotional perceptions that consumers add to certain brands" (Ahmad, 2011). We assume that the customers' emotional perceptions also increase the loyalty of the customer to the brand. Moreover, we assume that the loyalty created by the customers makes positive comments about the brand, which will increase the brand's awareness. Hle: Brand Image (BI) affects Brand Awareness. Hlf: Brand Image (BI) positively affects loyalty.

\section{III.V. Awareness, Loyalty, and Usage}

Brand Awareness is the positive interpretation of a brand from mouth to mouth. Since brand awareness is high, it will mean the popularity of the brand and the number of users, creating an emotional connection for the brand. We can say this is high brand loyalty. Based on our research, we assume that brand awareness and brand loyalty will affect usage. $H 2$ : Brand awareness affects usage positively. H3: Loyalty positively affects usage. The model created in the light of all this information is shown in Figure I. 


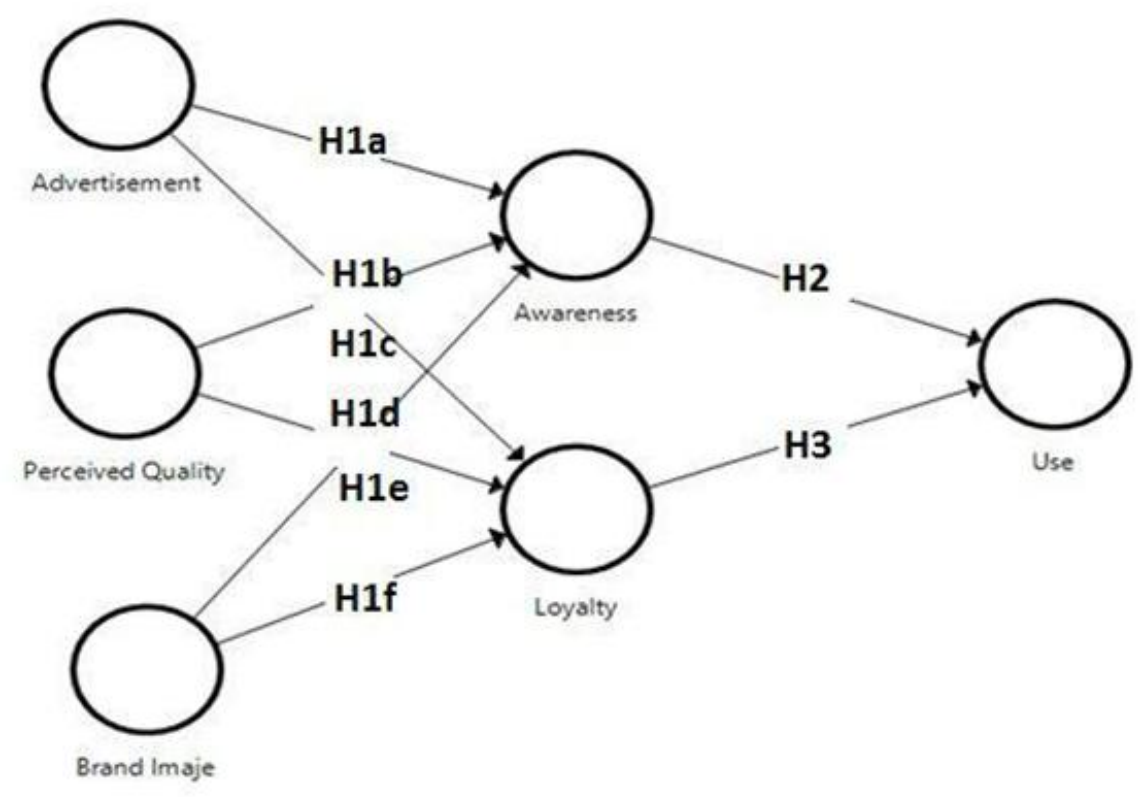

Figure I. The proposed model

\section{METHOD}

A quantitative approach was used to test the proposed model in this study. For this approach, firstly, a trial group was created, and the results were obtained. Seven factors (Advertising, Perceived Quality, Image, Awareness, Loyalty, and Use) were used among all groups and subjects. In both groups, participants were asked to fill out the questionnaire to answer which application they used between tourism-branded applications (Booking, Uber, Foursquare, Citymapper, Lonely Planet, Skyscanner). Participants who did not even use at least one of these applications were asked to answer the question, "Which features of the application would be more dominant in selecting the application?" if they were asked to choose one. This control group provided us with a basis for finding out to what extent the factors affecting usage affect a branded application. While developing the questionnaire, scales with validity and reliability were compiled in the literature, and some items were adapted for this study. The participants were asked to respond to the statements on a 5-point Likert scale ( $1=$ strongly disagree; $5=$ strongly agree). Many factors that are not included in the research model but are claimed to impact brand use in the literature are included as control variables. These variables are gender, age, education level, and weekly computer use. After removing 14 surveys with missing or unreliable answers from 360 face-to-face surveys, 346 valid surveys remained. 


\section{DATA ANALYSIS AND RESULTS}

The demographic characteristics of the participants are shown in Table 1. As shown in Table I, approximately half of the participants are women (53.2\%). Most of the participants were between 18 and 24 (51.7\%). The education level of about half of the respondents was associate degree (59.5\%). The majority of the respondents had a computer usage time of 0-5 hours per week (58.7).

Table I. Demographics

\begin{tabular}{|c|c|c|c|}
\hline & Variable & Frequency & Percent \\
\hline \multirow{2}{*}{ Gender } & Male & 162 & 46,8 \\
\hline & Female & 184 & 53,2 \\
\hline \multirow{5}{*}{ Age } & $18-24$ & 179 & 51,7 \\
\hline & $25-31$ & 102 & 29,5 \\
\hline & $33-38$ & 31 & 9 \\
\hline & $39-45$ & 7 & 2 \\
\hline & 46 and older & 27 & 7,8 \\
\hline \multirow{5}{*}{ Education } & High school & 46 & 13,3 \\
\hline & Vocational school & 206 & 59,5 \\
\hline & Undergraduate & 65 & 18,8 \\
\hline & Master & 10 & 2,9 \\
\hline & Ph.D & 19 & 5,5 \\
\hline \multirow{4}{*}{ Weekly Computer Usage } & $0-5$ hours & 203 & 58,7 \\
\hline & 6-10 hours & 57 & 16,5 \\
\hline & 11-20 hours & 32 & 9,2 \\
\hline & 21 hours and more & 54 & 15,6 \\
\hline
\end{tabular}

\section{Measurement Model}

The structures used were created using reflective indicators. Cronbach Alpha (CA), Composite Reliability (CR), and other composite reliability were used in matters that concern internal consistency. It is stated in the literature that these values should be higher than 0.70 (Henseler, 2009). Based on Table II, we can see that CA, CR, and other composite reliability values are higher than 0.7 , which shows that it has structural internal consistency (Wimmer \& Yoon, 2017). According to the results, the mean-variance (AVE) value should be greater than 
0.5 to evaluate the validity (Fornell \& Larcker, 1981). It is seen that the values of all constructs in Table II are more significant than 0.5 . Therefore, we can say that all constructs have convergent validity. As a result, Fornell-Larcker analysis shows that the square root of AVEs for each factor is larger than the correlations with other constructs (Table III).

Table II. Construct Reliability and Validity

\begin{tabular}{llccc}
\hline & $\begin{array}{l}\text { Cronbach's } \\
\text { Alpha(CA) }\end{array}$ & rho_A & $\begin{array}{c}\text { Composite } \\
\text { Reliability(CR) }\end{array}$ & $\begin{array}{c}\text { Average Variance } \\
\text { Extracted (AVE) }\end{array}$ \\
\hline Advertisement & 0,778 & 0,801 & 0,869 & 0,689 \\
\hline Awareness & 0,861 & 0,866 & 0,906 & 0,707 \\
\hline Brand Image & 0,724 & 0,778 & 0,843 & 0,643 \\
\hline Loyalty & 0,71 & 0,808 & 0,868 & 0,767 \\
\hline Perceived & 0,785 & 0,842 & 0,86 & 0,614 \\
Quality & 0,871 & 0,878 & 0,906 & 0,66 \\
\hline Use & & & & \\
\hline
\end{tabular}

Table III. Fornell-Larcker Criterion

\begin{tabular}{llllll} 
& Advertisement & Awareness & $\begin{array}{l}\text { Brand } \\
\text { Image }\end{array}$ & Loyalty & $\begin{array}{l}\text { Perceived } \\
\text { Quality }\end{array}$ \\
\hline Advertisement & $\mathbf{0 , 8 3 0}$ & & & & \\
\hline Awareness & 0,293 & $\mathbf{0 , 8 4 1}$ & & & \\
\hline Brand Image & 0,290 & 0,503 & $\mathbf{0 , 8 0 2}$ & & \\
\hline Loyalty & 0,266 & 0,279 & 0,460 & $\mathbf{0 , 8 7 6}$ & \\
\hline Perceived Quality & 0,251 & 0,383 & 0,473 & 0,318 & $\mathbf{0 , 7 8 3}$ \\
\hline Use & 0,349 & 0,522 & 0,515 & 0,452 & 0,599
\end{tabular}

Before testing the structure model, the measurement model was evaluated. First, all stimulus loads and states are examined in Table IV; the external loading must be greater than loading on all other constructs (Hair Jr et al., 2016). It examines the load of the measured variables on other structures. Each measured variable loads the highest loads according to its hidden structure and shows distinctive validity. 
Table IV. Outer Loading

\begin{tabular}{|c|c|c|c|c|c|c|}
\hline & Advertisement & Awareness & $\begin{array}{l}\text { Brand } \\
\text { Image }\end{array}$ & Loyalty & $\begin{array}{l}\text { Perceived } \\
\text { Quality }\end{array}$ & Use \\
\hline$\overline{\text { BA1 }}$ & 0,776 & & & & & \\
\hline BA2 & 0,868 & & & & & \\
\hline$\overline{\text { BA3 }}$ & 0,844 & & & & & \\
\hline BAW1 & & 0,872 & & & & \\
\hline BAW2 & & 0,847 & & & & \\
\hline BAW3 & & 0,844 & & & & \\
\hline BAW4 & & 0,798 & & & & \\
\hline BI1 & & & 0,683 & & & \\
\hline BI2 & & & 0,833 & & & \\
\hline BI3 & & & 0,878 & & & \\
\hline BL1 & & & & 0,819 & & \\
\hline BL2 & & & & 0,930 & & \\
\hline PQ1 & & & & & 0,857 & \\
\hline PQ2 & & & & & 0,873 & \\
\hline PQ3 & & & & & 0,821 & \\
\hline PQ4 & & & & & 0,533 & \\
\hline BU1 & & & & & & 0,733 \\
\hline BU2 & & & & & & 0,836 \\
\hline BU3 & & & & & & 0,841 \\
\hline BU4 & & & & & & 0,798 \\
\hline BU5 & & & & & & 0,848 \\
\hline
\end{tabular}

Martins et al. (2019) reviewed three criteria to evaluate discriminant validity and that the structures are distinctive if they meet these criteria. These criteria should be 1) higher than the correlation between square root structures of AVE 2) loads should be greater than cross loads 3) Heterotrait-Monotrait correlation (Table V) ratio (HTMT) should be less than 0.900 (Henseler, 2015). Finally, Cross-Loadings were calculated, and all structures showed high values compared to other reflective constructs (Table VI) (Hwang \& Choi, 2017). 
Table V. Heterotrait-Monotrait Ratio (HTMT)

\begin{tabular}{|c|c|c|c|c|c|c|}
\hline & Advertisement & Awareness & $\begin{array}{l}\text { Brand } \\
\text { Imaje }\end{array}$ & Loyalty & $\begin{array}{l}\text { Perceived } \\
\text { Quality }\end{array}$ & Use \\
\hline \multicolumn{7}{|l|}{ Advertisement_ } \\
\hline Awareness_ & 0,350 & & & & & \\
\hline Brand Imaje_ & 0,382 & 0,624 & & & & \\
\hline Loyalty & 0,325 & 0,336 & 0,580 & & & \\
\hline Perceived Quality_ & 0,287 & 0,450 & 0,632 & 0,395 & & \\
\hline Use & 0,429 & 0,596 & 0,636 & 0,562 & 0,714 & \\
\hline
\end{tabular}

Table VI. Cross Loading

\begin{tabular}{lllllll}
\hline & Advertisement & Awareness & $\begin{array}{l}\text { Brand } \\
\text { Imaje }\end{array}$ & Loyalty & $\begin{array}{l}\text { Perceived } \\
\text { Quality }\end{array}$ & Use \\
\hline BA1 & $\mathbf{0 , 7 7 6}$ & 0,213 & 0,220 & 0,165 & 0,132 & 0,306 \\
\hline BA2 & $\mathbf{0 , 8 6 8}$ & 0,231 & 0,241 & 0,204 & 0,213 & 0,326 \\
\hline BA3 & $\mathbf{0 , 8 4 4}$ & 0,277 & 0,257 & 0,274 & 0,259 & 0,252 \\
\hline BAW1 & 0,226 & $\mathbf{0 , 8 7 2}$ & 0,460 & 0,258 & 0,335 & 0,463 \\
\hline BAW2 & 0,292 & $\mathbf{0 , 8 4 7}$ & 0,394 & 0,230 & 0,314 & 0,443 \\
\hline BAW3 & 0,290 & $\mathbf{0 , 8 4 4}$ & 0,461 & 0,254 & 0,352 & 0,423 \\
\hline BAW4 & 0,170 & $\mathbf{0 , 7 9 8}$ & 0,368 & 0,189 & 0,282 & 0,428 \\
\hline BI1 & 0,247 & 0,323 & $\mathbf{0 , 6 8 3}$ & 0,253 & 0,346 & 0,365 \\
\hline BI2 & 0,173 & 0,406 & $\mathbf{0 , 8 3 3}$ & 0,306 & 0,392 & 0,343 \\
\hline BI3 & 0,276 & 0,463 & $\mathbf{0 , 8 7 8}$ & 0,498 & 0,403 & 0,508 \\
\hline BL1 & 0,153 & 0,167 & 0,277 & $\mathbf{0 , 8 1 9}$ & 0,227 & 0,327 \\
\hline BL2 & 0,289 & 0,299 & 0,491 & $\mathbf{0 , 9 3 0}$ & 0,317 & 0,448 \\
\hline PQ1 & 0,224 & 0,331 & 0,379 & 0,256 & $\mathbf{0 , 8 5 7}$ & 0,504 \\
\hline PQ2 & 0,266 & 0,374 & 0,402 & 0,289 & $\mathbf{0 , 8 7 3}$ & 0,531 \\
\hline PQ3 & 0,180 & 0,283 & 0,412 & 0,296 & $\mathbf{0 , 8 2 1}$ & 0,515 \\
\hline PQ4 & 0,058 & 0,169 & 0,288 & 0,108 & $\mathbf{0 , 5 3 3}$ & 0,275 \\
\hline BU1 & 0,292 & 0,314 & 0,338 & 0,371 & 0,548 & $\mathbf{0 , 7 3 3}$ \\
\hline BU2 & 0,311 & 0,399 & 0,301 & 0,482 & $\mathbf{0 , 8 3 6}$ \\
\hline BU3 & 0,286 & 0,460 & 0,379 & 0,451 & $\mathbf{0 , 8 4 1}$ \\
\hline BU4 & 0,219 & 0,479 & 0,346 & 0,498 & $\mathbf{0 , 7 9 8}$ \\
\hline BU5 & 0,305 & 0,420 & 0,442 & 0,475 & $\mathbf{0 , 8 4 8}$ \\
\hline & 0,426 & & & \\
\hline
\end{tabular}


Orman, A. \& Sebetci, Ö. 2021. Brand impact on the use of mobile applications. International Review of Economics and Management, 9(2),

Table VII. Bootstrapping Path Coefficients for Physician's Model

\begin{tabular}{|c|c|c|c|c|c|}
\hline & $\begin{array}{l}\text { Original } \\
\text { Sample }(\beta)\end{array}$ & $\begin{array}{l}\text { T } \quad \text { Statistics } \\
(\mid \text { O/STDEV } \mid)\end{array}$ & P Values & R Square & Decision \\
\hline Advertisement > Awareness_ & 0.140 & 2.500 & 0.012 & \multirow{3}{*}{0,298} & Accepted \\
\hline Brand Imaje > Awareness__ & 0.383 & 5.380 & 0.000 & & Accepted \\
\hline Perceived Quality> Awareness_ & 0.166 & 2.459 & 0.014 & & Accepted \\
\hline Advertisement > Loyalty & 0.131 & 2.717 & 0.007 & \multirow{3}{*}{0,240} & Accepted \\
\hline Brand Imaje > Loyalty & 0.369 & 5.923 & 0.000 & & Accepted \\
\hline Perceived Quality > Loyalty & 0.111 & 1.997 & 0.046 & & $\overline{\text { Accepted }}$ \\
\hline Awareness > Use & 0.431 & 7.377 & 0.000 & \multirow{2}{*}{0,375} & Accepted \\
\hline Loyalty > Use & 0.332 & 6.985 & 0.000 & & Accepted \\
\hline
\end{tabular}

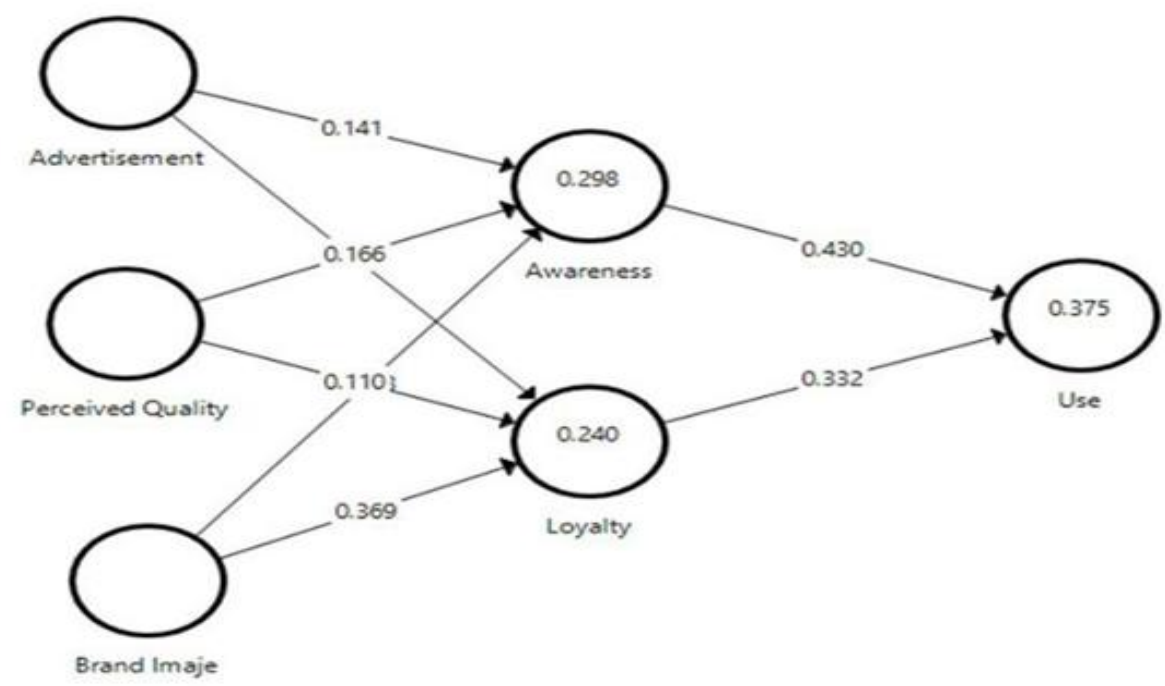

Figure II. Model Results

The hypotheses created in this study were confirmed using PLS-SEM. A bootstrapping procedure was used to evaluate the importance of hypothesized paths independent variables and the amount of variance attributed to explanatory variables (Chin, 1998). Table VII shows the path coefficients. The coefficient of determination for the dependent variables required to evaluate the structural equation model is R2. The path coefficient is $\beta$ (Henseler, Ringle \& Sinkovics, 2009). In order to evaluate the capacity of the structural equation model, it has been stated that the value of R2 should be above the value of 0.1 (Falk \& Miller, 1992). It is shown in Table 7 that R2 is more significant than 0.1 for our dependent variables (Awareness, 
Loyalty, Use). It is seen in Table VII that all hypotheses are supported according to the data received.

\section{CONCLUSION AND DISCUSSION}

Although mobile applications have increased rapidly, experimental research on this subject is shallow (Kim, Lin \& Sung, 2013; Kim, Wang \& Malthouse, 2015). Branded mobile applications literature reveals many factors related to the concept, how these factors are applied, and the sample size (Tan et al., 2017). The studies' scope and depth emphasize how factors should be combined to increase the use of mobile applications. This study aimed to explain the factors that affect mobile applications' use and their importance in terms of usage.

The proliferation of mobile applications, which has emerged recently and continues to increase, has enabled advertisers to recognize branded applications' potential to be effective marketing communication and consumer participation tools. The study aims to determine whether brand awareness and brand loyalty positively impact mobile application use. Therefore, the study has guiding effects for researchers, mobile app developers, travel agencies, and government agencies. It contributes to the academic literature on mobile applications in tourism from a developing market perspective.

Almost every industry monitors and adapts its mobile application-based services even when connecting them to social media channels with high usage rates. The tourism sector is one of the most critical sectors in this sense (Gulbahar \& Yıldırım, 2015). Our findings show that the majority of the worldwide brands investigated in this study had a direct and positive impact on the adoption of branded applications. The findings reveal that major big brands provide mobile environments in which branded app users may easily "manage" the views of all apps. Consumers freely engage with brands through labeled applications and proceed at their own pace through the application content thanks to the enhanced features of mobile applications. In addition to the brand image of the applications, it has been demonstrated that advertisements, quality, brand awareness, and loyalty positively affect general usage. Mobile applications are developed as a communication tool that turns all the information sought in a traditional web environment into a highly interactive and personalized modification in different user contexts (Kim, Lin \& Sung, 2013). Therefore, the current study to gain insight into this communication tool; has examined consumers' usage status when interacting with branded mobile applications. 
Customer engagement with branded mobile applications is critical for utilization, according to our findings. Branded mobile application users, according to this approach, are active consumers who have underlying motivations and seek specific types of applications when downloading or using mobile applications, rather than passive consumers who are expected to respond to the technology provided in traditional research. As a result of this approach, it is also necessary to concentrate on the elements that influence customer acceptance of branded mobile applications. It is quite important to consider what consumers do with branded mobile apps and what they receive from them. This means that consumers' interaction with branded mobile applications can be an essential source of value and shape their ultimate satisfaction and purchase intent. On the other hand, manufacturers should be encouraged to think about innovations that make applications more intelligent and updated about what users care.

Developing mobile application technologies research; explains the relationship between consumers' past experiences and price attitudes and their intention to use new mobile applications. People with smartphone use experience show high technological compliance in value and usability, causing positive attitudes towards price change and an increased possibility of using new smartphone applications related to tourism (Wang, 2019).

In another aspect, this study's results can help understand how existing branded apps offer mobile technologies to engage consumers. Besides, the findings reveal the need to discover innovations with quality, the proper advertisement, adequately prepared brand image, and make valuable suggestions about the future direction of mobile marketing communication while developing a wide range of mobile applications.

The findings give brand app builders strategic information about how to design app interfaces and what content to include in mobile apps to increase app engagement. Brand specialists can decide which application elements should be included in the apps and which should be upgraded based on customer interaction strategies produced by global brands, products, and services.

The study shows that loyalty from known and quality branded practice increases cognitive responses and lowers emotional responses. In this study, the design of branded applications, brand image, quality, and advertisement in consumer decision making; has revealed a clear finding that this leads to awareness and loyalty, directly affecting usage. 


\section{VII.LIMITATIONS AND FUTURE RESEARCH}

Although this research focuses on brand awareness and usage of branded apps, future research can examine the following areas to examine the benefits users receive in an app environment. First, this study was performed in Turkey's Aegean region culture; therefore, future research should be repeated to confirm this study's findings in another context. This will lead to further evidence of these factors' nature and impact on user satisfaction and purchase intent. Secondly, the current study focuses on a few specific brands, and more different branded mobile applications should be examined. However, given the relatively small sample size (346) compared to the number of applications described in this study, the situation may differ when researchers examine the larger sample.

The generalizability of this analysis is limited, despite the fact that it demonstrates its consequences on application developers. Because this study only looked at the state of a few branded applications, it tried to find out what factors influence usage status in branded apps. The study's conclusions are limited since other areas of experience generated based on the consumer's belief have not been assessed, despite the fact that it seeks to analyze every potential component of branded applications in depth (Calder, Malthouse \& Schaedel, 2009). As a result, the investigation of whether a branded application is linked to engagement aspects was limited to the specific features of the branded applications reported and investigated in this study. Finally, the validity of the rate difference tests performed in this study may have some limits.

\section{Etik Kurul Onayl:}

Bu çalışma için etik kurul onayı, Ankara Yıldırım Beyazıt Üniversitesi Etik Kurulundan 20/12/2021 tarih ve 2021-543 belge numarası ile alınmıştır.

\section{Ethics Committee Approval:}

Ethics committee approval was received for this study from Ankara Ylldrrtm Beyazt University, Ethics Committee on 20/12/2021 and 2021-543 document number.

Bu makale araştırma ve yayın etiğine uygun olarak hazırlanmış ve Turnitin kullanılarak intihal taraması yapılmıştır.

(This article was prepared in line with research and publication ethics and scanned for plagiarism by using Turnitin.) 


\section{REFERENCES}

Aaker, D. (1991). Managing Brand Equity: Capitalizing on the Value of Brand Name. New York, NY.:The Free Press.

Aaker, D. A. (2009). Managing brand equity. Simon and Schuster.

Ababio, A. G., \& Yamoah, E. E. (2016). Effect of advertising on the brand loyalty of cosmetic products among college students. International Review of Management and Marketing, 6(1).

Ahmad, U. (2011). What makes customers brand loyal: A study on telecommunication sector of Pakistan. International Journal of Business and Social Science, , 2(14), 213-221.

Al-Hawari, M. A. (2011). Do online services contribute to establishing brand equity within the retail banking context? Journal of Relationship Marketing, 10(3), 145-166.

Alnawas, I., \& Aburub, F. (2016). The effect of benefits generated from interacting with branded mobile apps on consumer satisfaction and purchase intentions. Journal of Retailing and Consumer Services, 31, 313-322.

Barnes, S. J., Mattsson, J., \& Sørensen, F. (2014). Destination brand experience and visitor behavior: Testing a scale in the tourism context. Annals of Tourism Research, 48, 121-139.

Bellman, S., Potter, R. F., Treleaven-Hassard, S., Robinson, J. A., \& Varan, D. (2011). The effectiveness of branded mobile phone apps. Journal of Interactive Marketing, 25(4), 191-200.

Bennett, W. N., \& Boraas, M. E. (1988). Isolation of a fast-growing strain of the rotifer brachionus calyciflorus pallas using turbidostat culture. Aquaculture, 73(1-4), 27-36.

Calder, B. J., Malthouse, E. C., \& Schaedel, U. (2009). An experimental study of the relationship between online engagement and advertising effectiveness. Journal of interactive marketing,23(4), 321-331.

Chin, W. W. (1998). Commentary: Issues and opinion on structural equation modeling.

Falk, R. F., \& Miller, N. B. (1992). A primer for soft modelling. Ed. Univ of Akron Pr, Akron, Ohio.

Fang, Y. H. (2019). An app a day keeps a customer connected: Explicating loyalty to brands and branded applications through the lens of affordance and service-dominant logic. Information and Management, 56(3), 377-391.

Fornell, C., \& Larcker, D. F. (1981). Structural equation models with unobservable variables and measurement error: Algebra and statistics.

Green, C. E., \& Lomanno, M. V. (2012). Distribution Channel Analysis: A guide for hotels. McLean: HSMAI foundation.

Gross, N. (2004). Applications of subdivision techniques in product development. Ph.D. dissertation, Technical University Berlin, Berlin, Germany, 2004.

Gulbahar, M. O., \& Yildirim, F. (2015). Marketing efforts related to social media channels and mobile application usage in tourism: Case study in Istanbul. Procedia-Social and Behavioral Sciences, 195, 453-462.

Hair Jr, J. F., Hult, G. T., Ringle, C., \& Sarstedt, M. (2016). A primer on partial least squares structural equation modeling (PLS-SEM). Sage publications.

Henseler, J. R. (2009). Emerald Group Publishing Limited. 277-319.

Henseler, J. R. (2015). A new criterion for assessing discriminant validity in variance-based structural equation modeling. Journal of the academy of marketing science, 43(1), 115-135.

Henseler, J., Ringle, C. M., \& Sinkovics, R. R. (2009). The use of partial least squares path modeling in international marketing. In New challenges to international marketing, 277-319.

Hwang, K., \& Choi, M. (2017). Effects of innovation-supportive culture and organizational citizenship behavior on e-government information system security stemming from mimetic isomorphism. Government Information Quarterly, 34(2), 183-198.

Jacoby, J. (1971). Model of multi-brand loyalty. Journal of advertising research, 11(3), 25-31.

Khan, A. A., Jadoon, S., \& Tareen, N. A. K. (2016). Impact of advertising on brand awareness and commitment in female apparel industry. International Journal of Academic Research in Business and Social Sciences, 6(3), 79-94. 
Kim, D., \& Adler, H. (2011). Students' use of hotel mobile apps: Their effect on brand loyalty. Paper presented at the 16 th Graduate Students Research Conference. Houston, TX.

Kim, E., Lin, J. S., \& Sung, Y. (2013). To app or not to app: Engaging consumers via branded mobile apps. Journal of Interactive Advertising, 13(1), 53-65.

Kim, S. J., Wang, R. J., \& Malthouse, E. C. (2015). The effects of adopting and using a 'brand's mobile application on 'customers' subsequent purchase behavior. Journal of Interactive Marketing,31, 28-41.

Koniewski, M. (2012). Brand awareness and customer loyalty. Polonya: PMR Research, 1-5.

Li, C. Y., \& Fang, Y. H. (2019). Predicting continuance intention toward mobile branded apps through satisfaction and attachment. Telematics and Informatics, 43, 101248.

Maria, S., Pusriadi, T., Hakim, Y. P., \& Darma, D. C. (2019). The effect of social media marketing, word of mouth, and effectiveness of advertising on brand awareness and intention to buy. Jurnal Manajemen Indonesia, 19(2), 107-122.

Martins, J., Branco, F., Gonçalves, R., \& Au-Yong-Ol. (2019). Assessing the success behind the use of education management information systems in higher education. Telematics and Informatics, 38, 182-193

Omoruyi, O., \& Chinomona, E. (2019). Evaluating the effects of brand advertising, brand element and brand awareness on purchasing intention. Journal of Contemporary Management, 16(1), 422-449.

Picoto, W. N., Duarte, R., \& Pinto, I. (2019). Uncovering top-ranking factors for mobile apps through a multi method approach. Journal of Business Research, 101, 668-674.

Pieters, R., Warlop, L., \& Wedel, M. (2002). Breaking through the clutter: Benefits of advertisement originality and familiarity for brand attention and memory. Management science, 48(6), 765-781.

Pnevmatikos, N., Vardar, B., \& Zaccour, G. (2018). When should a retailer invest in brand advertising? European Journal of Operational Research, 267(2), 754-764.

Rauschnabel, P. A., Felix, R., \& Hinsch, C. (2019). Augmented reality marketing: How mobile AR-apps can improve brands through inspiration. Journal of Retailing and Consumer Services, 49, 43-53.

Sasmita, J., \& Mohd Suki, N. (2015). Young consumers' insights on brand equity: Effects of brand association, brand loyalty, brand awareness, and brand image. International Journal of Retail and Distribution Management, 43(3), 276-292.

Sawant, R. P. (2012). Impact of advertising on brand awareness and consumer preference (with special reference to mens wear). Journal of Business and Management, 5(6), 54-61.

Tan, G. W., Lee, V. H., Lin, B., \& Ooi, K. B. (2017). Mobile applications in tourism: the future of the tourism industry?. Industrial Management and Data Systems, 117(3), 560-581.

Uztug, F. (2003). Markan Kadar Konus. Marka Iletisimi Stratejileri, Istanbul: MediaCat Kitaplarl.

Van Noort, G., \& van Reijmersdal, E. A. (2019). Branded apps: explaining effects of 'brands' mobile phone applications on brand responses. Journal of Interactive Marketing, 45, 16-26.

Wang, W. (2019). The influence of perceived technological congruence of smartphone application and air travel experience on consumers' attitudes toward price change and adoption. Journal of Hospitality and Tourism Technology., 10(2), 1-20.

Wimmer, H., \& Yoon, V. Y. (2017). Counterfeit product detection: Bridging the gap between design science and behavioral science in information systems research. Decision Support Systems, 104, 1-12. 